Original Research Article

\title{
Outcomes of Transvaginal Anterior Levatorplasty with Posterior Colporrhaphy for Symptomatic Rectocele
}

\author{
Kotaro Maeda ${ }^{1)}$, Katsuyuki Honda ${ }^{2)}$, Yoshikazu Koide ${ }^{3)}$, Hidetoshi Katsuno ${ }^{4)}$, Tsunekazu Hanai ${ }^{3)}$, Koji Masumori ${ }^{3)}$, \\ Hiroshi Matsuoka ${ }^{3)}$, Tomoyoshi Endo ${ }^{4)}$ and Yeong Cheol Cheong ${ }^{3)}$ \\ 1) International Medical Center Fujita Health University Hospital, Toyoake, Japan \\ 2) Division of Surgery, Rokuwa Hospital, Inazawa, Japan \\ 3) Department of Surgery, Fujita Health University School of Medicine, Toyoake, Japan \\ 4) Department of Surgery, Fujita Health University Okazaki Medical Center, Okazaki, Japan
}

\begin{abstract}
Objectives: To clarify the long-term outcomes of transvaginal anterior levatorplasty with posterior colporrhaphy for symptomatic rectocele with defecographic changes.

Methods: Consecutive patients undergoing transvaginal anterior levatorplasty with posterior colporrhaphy for symptomatic rectocele were prospectively registered and retrospectively reviewed using medical records. Symptoms, fecal incontinence, and defecographic findings were evaluated before and after surgery.

Results: Fifty-seven women (mean age, 68 years) were identified, and the median disease duration was 24 months. Symptoms of vaginal mass $(\mathrm{n}=32)$ and difficult defecation $(\mathrm{n}=21)$ disappeared $(90.6 \%$ and $71.4 \%$, respectively) or improved (6.3\% and $28.6 \%$, respectively) after surgery. However, the feeling of residual stool was unchanged in two of eight patients. Seventeen patients who performed digitation on defecation before surgery discontinued digitation after surgery. The proportion of patients who had fecal incontinence preoperatively (40.4\%) decreased significantly after surgery (17.5\%) during a median follow-up period of 47 months. Defecography revealed a disappearance or improvement of rectocele in all 18 patients examined. The average rectocele size decreased significantly in six improved patients $(p=0.0006$, paired ttest).

Conclusions: Transvaginal anterior levatorplasty with posterior colporrhaphy for symptomatic rectocele was a useful option to improve symptoms and anatomical disorders in the long term, but it had limitations in improving defecatory symptoms.
\end{abstract}

\section{Keywords}

rectocele repair, anterior levatorplasty, transvaginal approach, defecation disorder, fecal incontinence

J Anus Rectum Colon 2021; 5(2): 137-143

\section{Introduction}

Rectocele, a type of pelvic organ prolapse, is a common condition in women, but most cases are asymptomatic[1]. When rectocele becomes symptomatic, it induces defecatory disorders, constipation, vaginal mass, pelvic discomfort, and so on[2]. Patients with symptomatic rectocele sometimes need digitation on defecation, and these symptoms often decrease the patients' quality of life[3]. Rectocele is considered to be due to rectovaginal septum weakness, and several procedures, such as transanal[3-5], transperineal[6-8], transvaginal[2,9], laparoscopic repairs with or without mesh[10], 

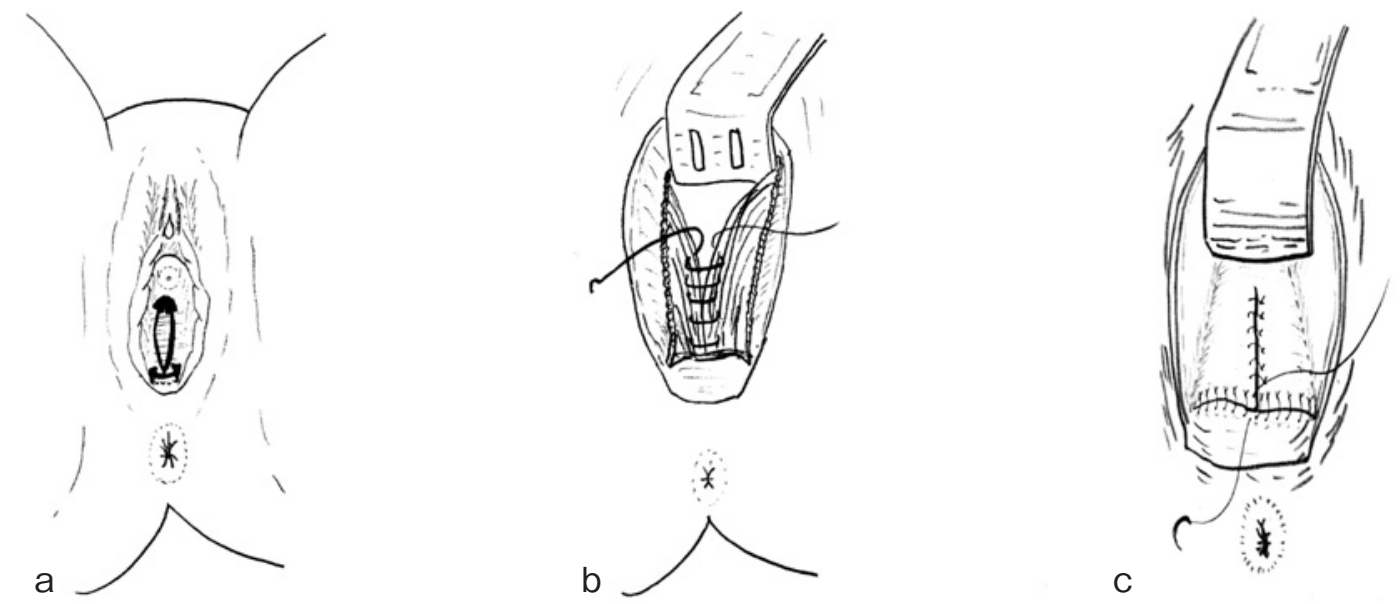

Figure 1. Schema of transvaginal anterior levatorplasty with posterior colporrhaphy.

(a) Incision; (b) anterior levatorplasty; (c) closure.

stapler repairs[11,12], and a combination of the abovementioned procedures, have been used for rectocele repair $[5,9,10]$. However, rectocele repair does not always alleviate symptoms[11,13]. It might be due to the lack of strength of the repaired rectovaginal septum for supporting long-term constant defecation. Recent reports revealed that mesh erosion, pain, infection, bleeding, pain during intercourse, fistula formation, and so on had occurred after repairs using mesh[14-16]. Transvaginal anterior levatorplasty with posterior colporrhaphy for symptomatic rectocele to reinforce the rectovaginal septum without mesh had favorable short-term outcomes in a limited number of cases[2]. The principal aim of the present investigation was to clarify the long-term outcomes of transvaginal anterior levatorplasty with posterior colporrhaphy for symptomatic rectocele.

\section{Methods}

\section{Ethical information}

The protocol of this retrospective single-center cohort observation study was approved by the institutional review board of Fujita Health University (HM20-189), and the study was performed in accordance with the 1964 World Medical Association's Declaration of Helsinki and its later amendments. All patients gave their written informed consent to the surgical procedures prior to their operations.

\section{Patients}

Consecutive patients who underwent transvaginal anterior levatorplasty with posterior colporrhaphy for symptomatic rectocele between 1994 and September 2019 were prospectively registered and retrospectively reviewed using medical records.

The selection criteria for surgical repair were the presence of symptoms associated with rectocele and the existence of rectocele $>5 \mathrm{~cm}$ in depth by evacuation proctography (defecography). Surgery was adopted only when symptoms were considered to originate from rectocele and were not improved by conservative treatments. Total colonofiber and/or double-contrast barium enema studies were performed in all patients. A transit marker study was performed for patients with constipation and/or defecatory disorders. No patients had slow transit constipation or organic obstruction.

\section{Operative procedures}

After bowel preparation with whole-gut lavage, the operation was performed with the patient under general anesthesia in the lithotomy position, using procedures reported previously[2]. The operative field in the vagina was obtained using the Lone Star anal retractor and surgical spatula connected to an Octopus retractor holder. Before incision, 50 $\mathrm{mL}$ of epinephrine solution in normal saline $(1: 200,000)$ was injected into the rectovaginal septum from the vagina up to the retroperitoneal tissues behind the cervix. A transverse incision was initially performed in the posterior vaginal wall just above the sphincter muscles (Figure 1a), and a blunt dissection of the rectovaginal septum was made between the vaginal wall and the rectum. Meanwhile, a vertical or an inverse $\mathrm{V}$ - or U-shaped incision was performed in the posterior vaginal wall above the transverse incision to facilitate a full exposure of both limbs of the puborectalis and pubococcygeal muscles on either side of the midline upward behind the level of the posterior fornix. The protruding anterior rectal wall was excluded using swabs. Five or six mattress stitches with nonabsorbable 0 sutures were passed into each anterior limb of the puborectalis and pubococcygeal muscles and then tied securely from the proximal to distal end to reinforce and form the rectovaginal septum (Figure 1b). The field was irrigated with $200 \mathrm{~mL}$ saline to 


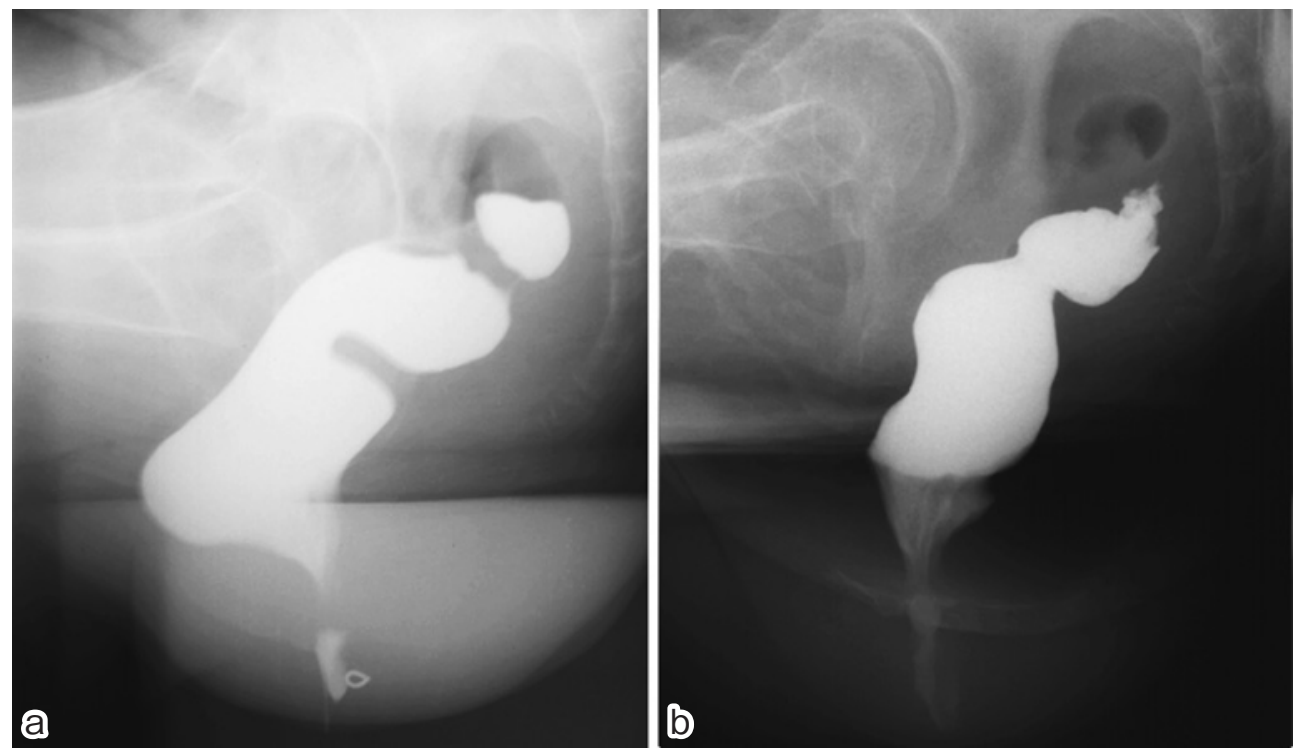

Figure 2. Defecographic change in the patient with the disappearance of rectocele after surgery.

(a) Before rectocele repair; (b) after rectocele repair.
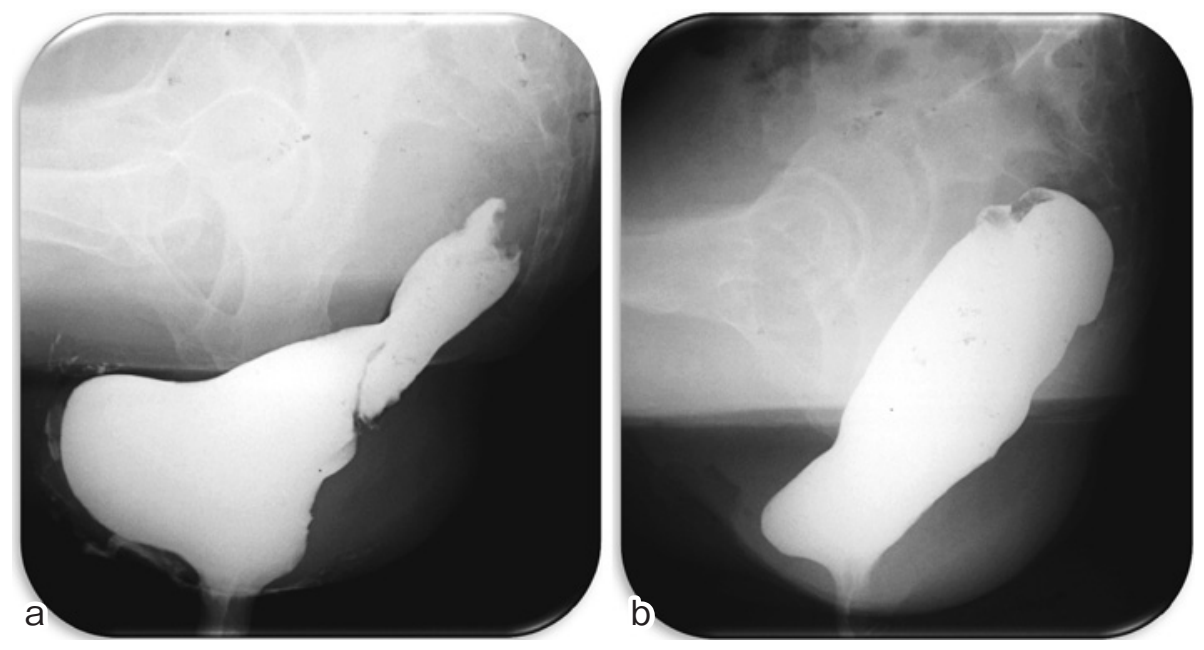

Figure 3. Defecographic change in the patient with the improved rectocele after surgery.

(a) Before rectocele repair; (b) after rectocele repair.

remove possible contamination. The redundant vaginal wall was trimmed, and each cut edge was sutured with absorbable 0 sutures. The transverse incision was closed with 000 absorbable sutures (Figure 1c).

\section{Evaluation}

The operative outcomes and postoperative morbidity and mortality were studied. Changes in symptoms and fecal and urinary continence were investigated based on medical records before surgery and at the time of the final follow-up. Changes in symptoms after surgery were classified as disappeared, improved, unchanged, and worsened. The performance of digitation was also evaluated before and after surgery. When defecography demonstrated a disappearance of rectocele after surgery, as shown in Figure 2, the change was classified as disappeared. However, when the rectocele size decreased, as shown in Figure 3, the change was classified as improved. The rectocele size was measured before and after surgery according to Yoshioka's method[1], and the change in size was studied in these improved cases.

\section{Statistical analyses}

Fisher's test and the paired t-test were used for statistical analyses, and differences were considered significant at $p<$ 0.05 . 
Table 1. Characteristics of the Diseases $(n=57)$.

\begin{tabular}{lr}
\hline Rectocele & 30 \\
Rectocele + enterocele & 7 \\
Rectocele + peritoneocele & 4 \\
Rectocele + hemorrhoids & 3 \\
Rectocele + rectal prolapse & 2 \\
Rectocele + rectal prolapse + sphincter injury & 2 \\
Rectocele + rectal prolapse + uterine prolapse & 1 \\
Rectocele + uterine prolapse + cystocele + sphincter injury & 2 \\
Rectocele + sphincter injury & 2 \\
Rectocele + mucosal prolapse & 2 \\
Rectocele + cystocele & 1 \\
Rectocele + rectal intussusception & 1 \\
\hline
\end{tabular}

Table 2. Characteristics of the Procedures $(n=57)$.

\begin{tabular}{lr}
\hline ALP & 32 \\
ALP + peritoneocele repair & 8 \\
ALP + sphincteroplasty & 5 \\
ALP + hemorrhoid repair & 2 \\
ALP + open rectopexy & 2 \\
ALP + laparoscopic rectopexy & 2 \\
ALP + laparoscopic rectopexy + sphincteroplasty & 1 \\
ALP + laparoscopic rectopexy + hysterectomy & 1 \\
ALP + Gant-Miwa procedure & 1 \\
ALP + cystocele repair & 1 \\
ALP + hysterectomy + cystocele repair + sphincteroplasty & 1 \\
ALP + peritoneocele excision & 1 \\
\hline
\end{tabular}

ALP, transvaginal anterior levatorplasty with posterior colporrhaphy.

\section{Results}

Fifty-seven patients were identified during the study period, and formed the subjects of this study. The average age of the patients was 68 years (range, 32-89 years), and all patients were female. The preoperative concomitant diseases are presented in Table 1. The concomitant diseases were surgically treated at the same time for each condition (Table 2). The most frequent preoperative symptom was vaginal mass, followed by difficult defecation, feeling of residual stool, feeling of pelvic pressure, and so on (Table 3). Of 57 patients, 17 (29.8\%) performed digitation on defecation preoperatively. Many patients had multiple symptoms. The median duration of symptoms was 24 months (range, 1-240 months). Of 57 patients, 23 (40.4\%) had fecal incontinence and $12(21.1 \%)$ had urinary incontinence preoperatively (Table 4). Preoperatively, five patients had undergone tensionfree vaginal mesh surgery for urinary dysfunction, and three, two, and two patients had undergone surgery for rectal prolapse, uterine prolapse, and cystocele, respectively (Table 5). Vaginal prolapse was treated conservatively in three patients.

The median duration of operation and bleeding volume
Table 3. Change in Symptoms after Surgery.

\begin{tabular}{|c|c|c|}
\hline Preoperative symptom & $\begin{array}{l}\text { Postoperative } \\
\text { change }\end{array}$ & $\mathrm{n}(\%)$ \\
\hline \multirow[t]{4}{*}{ Vaginal mass $(\mathrm{n}=32)$} & Disappeared & $29(90.6)$ \\
\hline & Improved & $2(6.3)$ \\
\hline & Unchanged & 0 \\
\hline & Worsened & $1(3.1)$ \\
\hline \multirow[t]{4}{*}{ Difficult defecation $(\mathrm{n}=21)$} & Disappeared & $15(71.4)$ \\
\hline & Improved & $6(28.6)$ \\
\hline & Unchanged & 0 \\
\hline & Worsened & 0 \\
\hline \multirow[t]{4}{*}{ Feeling of residual stool $(n=8)$} & Disappeared & $3(37.5)$ \\
\hline & Improved & $3(37.5)$ \\
\hline & Unchanged & $2(25.0)$ \\
\hline & Worsened & 0 \\
\hline \multirow[t]{4}{*}{ Feeling of pelvic pressure $(n=6)$} & Disappeared & $4(66.7)$ \\
\hline & Improved & $2(33.3)$ \\
\hline & Unchanged & 0 \\
\hline & Worsened & 0 \\
\hline \multirow[t]{4}{*}{ Vaginal discomfort $(n=4)$} & Disappeared & $4(100)$ \\
\hline & Improved & 0 \\
\hline & Unchanged & 0 \\
\hline & Worsened & 0 \\
\hline \multirow[t]{4}{*}{ Perianal pain $(n=3)$} & Disappeared & $1(33.3)$ \\
\hline & Improved & $2(66.7)$ \\
\hline & Unchanged & 0 \\
\hline & Worsened & 0 \\
\hline \multirow[t]{4}{*}{ Feeling of descent $(n=2)$} & Disappeared & $2(100)$ \\
\hline & Improved & 0 \\
\hline & Unchanged & 0 \\
\hline & Worsened & 0 \\
\hline Digitation $(\mathrm{n}=17)$ & Not performed & $17(100)$ \\
\hline
\end{tabular}

Table 4. Change in Continence in Rectocele Repair $(n=57)$.

\begin{tabular}{lcc}
\hline Type of continence & Before repair & After repair \\
\hline Fecal incontinence & $23(40.4)^{*}$ & $10(17.5)^{*}$ \\
Urinary incontinence & $12(21.1)$ & $7(12.3)$ \\
\hline
\end{tabular}

Values are presented as $\mathrm{n}(\%)$.

${ }^{*} p=0.013$ (Fisher's exact test).

Table 5. Surgical History for Concomitant Pelvic Organ Prolapse in Patients with Rectocele $(n=57)$.

\begin{tabular}{lclcc}
\hline $\begin{array}{c}\text { Pelvic organ } \\
\text { prolapse }\end{array}$ & $\begin{array}{c}\text { Before } \\
\text { ALP }\end{array}$ & $\begin{array}{c}\text { With } \\
\text { ALP }\end{array}$ & $\begin{array}{c}\text { After } \\
\text { ALP }\end{array}$ & $\begin{array}{c}\text { All } \\
\text { courses }\end{array}$ \\
\hline Cystocele & $2(3.5)$ & $3(5.3)$ & $5(8.8)$ & $10(17.5)$ \\
Rectal prolapse & $3(5.3)$ & $5(8.8)$ & $1^{*}(1.8)$ & $9(15.8)$ \\
Enterocele & 0 & $7(12.3)$ & $1^{*}(1.8)$ & $8(14.0)$ \\
Uterine prolapse & $2(3.5)$ & $3(5.3)$ & $1(1.8)$ & $6(10.5)$ \\
Mucosal prolapse & 0 & 0 & $1(1.8)$ & $1(1.8)$ \\
\hline
\end{tabular}

Values are presented as $\mathrm{n}(\%)$.

ALP: transvaginal anterior levatorplasty with posterior colporrhaphy.

*Surgery because of recurrence. 
Table 6. Size of Rectocele before and after Rectocele Repair in Improved Patients.

\begin{tabular}{ccccc}
\hline \multirow{2}{*}{$\begin{array}{c}\text { Patient } \\
\text { no. }\end{array}$} & $\begin{array}{c}\text { Age } \\
\text { (years) }\end{array}$ & Surgery performed & \multicolumn{2}{c}{ Size of rectocele $(\mathrm{cm})$} \\
\cline { 4 - 5 } & 51 & ALP + SP & 6.1 & Before \\
\hline 2 & 44 & ALP & 7.4 & 3.0 \\
3 & 43 & ALP + Lap-rectopexy & 5.6 & 2.6 \\
4 & 39 & ALP + Lap-rectopexy & 6.5 & 4.0 \\
5 & 57 & ALP + Lap-rectopexy & 6.2 & 3.2 \\
6 & 59 & ALP & 6.5 & 3.0 \\
Average (range) & & & $6.4(5.6-7.4) *$ & $3.4(2.6-4.0)^{*}$ \\
\hline
\end{tabular}

$* p=0.0006$ (paired t-test).

ALP: transvaginal anterior levatorplasty with posterior colporrhaphy; SP: sphincteroplasty; Lap-rectopexy: laparoscopic rectopexy.

were 89 minutes (range, 36-257 minutes) and $96 \mathrm{~mL}$ (range, 5-927 mL), respectively. An intraoperative rectal injury occurred in two $(3.5 \%)$ patients and was sutured during the surgery without further postoperative complications. These patients had undergone a previous vaginal surgery, performed by a gynecologist, for rectocele. Postoperative morbidity occurred in eight (13.6\%) patients after surgery and during the follow-up period. One hematoma that occurred in the rectovaginal septum after the surgery was drained from the vagina and healed subsequently. One small ischemic change on the skin over sphincter plication was treated conservatively and cured. Suture abscesses occurred in six (10.5\%) patients after surgery and during follow-up, and the suture threads were finally removed in these patients without further events. No deaths occurred during or after surgery.

The median follow-up period was 47 months (range, 1204 months). During the follow-up, nine (15.8\%) patients underwent additional surgeries for newly appeared pelvic organ prolapse (five cases of cystocele, and one case of uterine prolapse) and for the recurrence of concomitant diseases (one case each of mucosal prolapse, of recurrent rectal prolapse that occurred 9 years after surgery, and of recurrent enterocele that occurred 5 months after surgery) (Table 5).

The vaginal mass worsened in one $(3.1 \%)$ patient because of the recurrence of concomitant enterocele, as mentioned above (Table 3). She underwent additional peritoneal repair for enterocele[17] and had no further recurrent symptoms.

The proportion of patients who had fecal incontinence decreased significantly after surgery $(p=0.013$, Fisher's exact test, Table 4). The median fecal incontinence score according to the Cleveland Clinic scale[18] was 6 (range, 2-14) preoperatively, and it decreased to 0 (range, $0-10$ ) postoperatively $(p<0.0001$, paired t-test). Other types of urinary dysfunctions were observed in $17(29.8 \%)$ patients preoperatively, and they were confirmed in 12 patients (21.1\%) after surgery.

Only five patients performed sexual intercourse preoperatively. Dyspareunia was not observed in any patients postop- eratively; however, one patient complained of her vaginal narrow feeling during intercourse.

The postoperative defecography was performed in 18 (31.6\%) of 57 patients who underwent it preoperatively. It was performed at an average of 43 months (range, 1-48 months) after surgery. The postoperative defecography revealed a disappearance of rectocele in $12(66.7 \%)$ patients and an improvement of rectocele in $6(33.3 \%)$ patients. The size of rectocele decreased significantly in improved patients (Table $6, p=0.0006$, paired t-test).

\section{Discussion}

This study investigated the long-term outcomes of transvaginal anterior levatorplasty with posterior colporrhaphy for symptomatic rectocele with defecographic changes. Okamoto et al.[19] reported that concomitant pelvic organ prolapse occurred in $62.5 \%$ of patients with rectocele. In this study, 10 of 57 patients undergoing rectocele repair underwent previous treatments for other pelvic organ prolapse, and 18 patients underwent surgery for concomitant pelvic organ prolapse with rectocele repair. Furthermore, six patients underwent additional surgery for newly appeared pelvic organ prolapse during the follow-up. The most frequent concomitant pelvic organ prolapse during all courses of surgery of the patients was cystocele, followed by rectal prolapse, enterocele, uterine prolapse, and vaginal prolapse (Table 5). Therefore, collaborative work between gynecologists and urologists is required in the treatment of rectocele.

The selection criteria for the surgery and type of procedure are controversial in the treatment of rectocele[13,20,21]. The selection criteria for surgery might affect the outcomes of rectocele repair. An improvement of satisfaction after endorectal repair of rectocele has been observed to increase from $63 \%$ to $82 \%$ with more careful patient selection[22,23]. The selection criteria for surgery in this study were not so different from those in previous reports $[6,13,24]$. 
Complications after various rectocele repairs have occurred in $1-9 \%$ of patients[3,7,21,23,25], and most were minor complications. In this study, morbidity occurred in eight (13.6\%) patients after surgery and during the follow-up period. Suture abscess was observed in six $(10.5 \%)$ patients, but it subsided after suture removal. This might have been due to the use of nonabsorbable suture threads to reinforce the rectovaginal septum. Rectovaginal fistula had occurred in less than $1 \%$ of the patients after transanal repair in most studies $[23,24,26]$. No major complications or mortality was observed in this study.

Although favorable results have been achieved with various methods of repair, the overall failure rate after rectocele repair still ranges from $15 \%$ to $30 \%$ [13]. One of the advantages of performing anterior levatorplasty for rectocele repair is the restoration of a firm rectovaginal septum without using mesh and the reduction of the diameter of the levator hiatus, as shown on defecography in this study and in a previous report[2]. Although symptom improvement is not necessarily associated with the dimensions of rectocele in previous reports[4,13,27,28], the disappearance or improvement of symptoms with the disappearance and improvement of the size of rectocele, as shown in this study, might reflect the importance of the rectovaginal septum in the treatment of rectocele.

Several parameters have been used to evaluate the success rate of rectocele repairs, such as the interview of symptoms[2,4], symptomatic score[7], constipation scoring system[3,5,10], obstructed defecation syndrome score[10,12], fecal incontinence severity index[3,10], quality of life score $[3,6]$, and so on. The differences in evaluation methods might be due to the variety of symptoms presented by rectocele and/or the selection criteria for rectocele repair. The most important point for patients with symptomatic rectocele is symptom improvement; therefore, we evaluated the symptoms that the patients presented. Among several symptoms observed before surgery, vaginal mass, vaginal discomfort, and a feeling of descent had high frequency of complete disappearance $(90.6 \%, 100 \%$, and $100 \%$, respectively) after surgery, but worsened symptoms of vaginal mass were observed in one patient with the recurrence of concomitant enterocele (Table 3). Meanwhile, there was a limitation in the improvement of the feeling of residual stool (unchanged in two of eight patients after surgery). It was considered that another mechanism might be associated with this symptom.

Digitation on defecation might be a more objective parameter in evaluating the success rate. A study reported that the preoperative need for digitation correlated with a successful outcome after rectocele repair[29]. Preoperative digitation has been performed by $40-80 \%$ of patients with rectocele in previous reports[3,29-31]. Seventeen $(29.8 \%)$ patients performed digitation for evacuation preoperatively, and all discontinued digitation on defecation after surgery in our se- ries. This result was in accordance with the good results of the other symptoms evaluated here. It was considered that the reinforcement of the rectovaginal septum accomplished by this procedure might enable the discontinuation of digitation on defecation and improvement of symptoms.

Dyspareunia has been reported after transvaginal rectocele repair[9] However, no dyspareunia was observed in this study, although the number of patients who performed sexual intercourse was small. This might be due to the level of approximation of levator muscles.

Patients with rectocele experience some degree of fecal incontinence[2,3,32]. In this study, the number of patients with preoperative fecal incontinence decreased significantly after surgery, and the fecal incontinence score also decreased postoperatively. This might be due to the increase in squeeze pressure, which was observed after transvaginal anterior levatorplasty in a previous study[2] or the effect of additional sphincteroplasty in several patients.

The limitation of this study was the lack of established criteria to evaluate symptomatic results, which is due to the different symptoms of the patients and the wide-ranging follow-up period. The postoperative defecography was performed only in $18(31.6 \%)$ patients to evaluate the success rate of the structural repair by this procedure. A constipation score, such as the obstructed defecation syndrome score, was not used in this study to evaluate the symptomatic improvements of constipation. Furthermore, this retrospective study was conducted in a single institution. Comprehensive methods to evaluate the results of rectocele repairs might be needed in further studies.

In conclusion, transvaginal anterior levatorplasty with posterior colporrhaphy for rectocele was a useful option to improve symptoms and anatomical disorders in the long term, but it had some limitations in improving defecatory symptoms, such as the feeling of residual stool.

\section{Acknowledgements}

We would like to thank Editage (www.editage.com) for English language editing.

\section{Conflicts of Interest}

There are no conflicts of interest.

Approval by Institutional Review Board (IRB)

Approval code: HM20-189 by Fujita Health University

\section{Author Contributions}

K M, K H, Y K, H K, T H, K M, H M, T E, and Y C contributed to the study conception and design. Material preparation, data collection, and analysis were performed by $\mathrm{K} \mathrm{M}$. The first draft of the manuscript was written by $\mathrm{K} \mathrm{M}$, and all authors commented on previous versions of the manuscript. All authors read and approved the final manu- 
script.

\section{Disclaimer}

Hidetoshi Katsuno is one of the Associate Editors of Journal of the Anus, Rectum and Colon and on the journal's Editorial Board. He was not involved in the editorial evaluation or decision to accept this article for publication at all.

\section{References}

1. Yoshioka K, Matsui Y, Yamada O, et al. Physiological and anatomic assessment of patients with rectocele. Dis Colon Rectum. 1991 Aug; 34(8): 704-8.

2. Maeda K, Maruta M, Hanai T, et al. Transvaginal anterior levatorplasty with posterior colporrhaphy for symptomatic rectocele. Tech Coloproctol. 2003 Oct; 7(3): 181-5.

3. Tsunoda A, Takahashi T, Kusanagi H. Transanal repair of rectocele: prospective assessment of functional outcome and quality of life. Colorectal Dis. 2020 Feb; 22(2): 178-86.

4. Van Laarhoven CJHM, Kamm MA, Bartram CI, et al. Relationship between anatomical and symptomatic long-term results after rectocele repair for impaired defecation. Dis Colon Rectum. 1999 Feb; 42(2): 204-11.

5. Kim JH, Kim DH, Lee YP. Long-term comparison of physiological anorectal changes and recurrence between transanal repair and transanal repair with posterior colporrhaphy in rectocele. Asian J Surg. 2020 Jan; 43(1): 265-71.

6. Balata MB, Elgendy H, Emile SH, et al. Functional outcome and sexual-related quality of life after transperineal versus transvaginal repair of anterior rectocele: a randomized clinical trial. Dis Colon Rectum. 2020 Apr; 63(4): 527-37.

7. Lamah M, Ho J, Leicester RJ. Results of anterior levatorplasty for rectocele. Colorectal Dis. 2001 Nov; 3(6): 412-6.

8. Ommer A, Köhler A, Athanasiadis S. Results of transperineal levatorplasty in treatment of symptomatic rectocele. Chirurg. 1998 Sep; 69(9): 966-72.

9. Lourenço TRM, Pergialiotis V, Durnea CM, et al. A systematic review of reported outcomes and outcome measures in randomized trials evaluating surgical intervention for posterior vaginal prolapse to aid development of a core outcome set. Int J Gynecol Obstet. 2020 Mar; 148(3): 271-81.

10. Van der Hagen SJ, van Gemert WG, Soeters PB, et al. Transvaginal posterior colporrhaphy combined with laparoscopic ventral mesh rectopexy for isolated Grade III rectocele: a prospective study of 27 patients. Colorectal Dis. 2012 Nov; 14(11): 1398-402.

11. Lehur PA, Pravini B, Christoforidis D. To stapler or not to stapler the symptomatic rectocele. Tech Coloproctol. 2020; 24(1): 1-3.

12. Harris MA, Ferrara A, Gallagher J, et al. Stapled transanal rectal resection vs. transvaginal rectocele repair for treatment of obstructive defecation syndrome. Dis Colon Rectum. 2009 Apr; 52(4): 592-7.

13. Stojkovic SG, Balfour L, Finan PJ, et al. Does the need to selfdigitate or the presence of a large or nonemptying rectocele on proctography influence the outcome of transanal rectocele repair? Colorectal Dis. 2003 Mar; 5(2): 169-72.

14. Altman D, Väyrynen T, Engh ME, et al. Anterior colporrhaphy versus transvaginal mesh for pelvic-organ prolapse. N Engl J Med. 2011 May; 364(19): 1826-36.

15. Brubaker L, Nygaard I, Richter HE, et al. Two-year outcomes after sacrocolpopexy with and without Burch to prevent stress urinary incontinence. Obstet Gynecol. 2008 Jul; 112(1): 49-55.

16. Koide Y, Maeda K, Hanai T, et al. Successful repair of a rectovaginal fistula caused by a tension-free vaginal mesh (TVM): a case report. J Anus Rectum Colon. 2018 Apr; 2(2): 66-9.

17. Maeda K, Koide Y, Katsuno H, et al. Transvaginal peritoneocele repair with anterior levatorplasty in patients with a rectocele and an enterocele. 2020 Oct 8. doi: 10.1007/s00595-020-02161-w.

18. Jorge JM, Wexner SD. Etiology and management of fecal incontinence. Dis Colon Rectum. 1993 Jan; 36(1): 77-97.

19. Okamoto N, Maeda $K$, Kato $R$, et al. Dynamic pelvic threedimensional computed tomography for investigation of pelvic abnormalities in patients with rectocele and rectal prolapse. J Gastroenterol. 2006 Sep; 41(8): 802-6.

20. Boccasanta $P$, Venturi $M$, Calabrò $G$, et al. Which surgical approach for rectocele? A multicentric report from Italian coloproctologists. Tech Coloproctol. 2001 Dec; 5(3): 149-56.

21. Ayabaca SM, Zbar AP, Pescatori M. Anal continence after rectocele repair. Dis Colon Rectum. 2002 Jan; 45(1): 63-9.

22. Khubchandani IT, Sheets JA, Stasik JJ, et al. Endorectal repair of rectocele. Dis Colon Rectum. 1983 Dec; 26(12): 792-6.

23. Khubchandani IT, Clancy JP 3rd, Rosen I, et al. Endorectal repair of rectocele revised. Br J Surg. 1997 Jan; 84(1): 89-91.

24. Janssen LW, van Dijke CF. Selection criteria for anterior rectal wall repair in symptomatic rectocele and anterior wall prolapse. Dis Colon Rectum. 1994 Nov; 37(11): 1100-7.

25. Murthy VK, Orkin BA, Smith LE, et al. Excellent outcome using selective criteria for rectocele repair. Dis Colon Rectum. 1996 Apr; 39(4): 374-8.

26. Sehapayak S. Transrectal repair of rectocele: an extended armamentarium of colorectal surgeons. A report of 355 cases. Dis Colon Rectum. 1985 Jun; 28(6): 422-33.

27. Capps WF. Rectoplasty and pericoloplasty for the symptomatic rectocele: a report of fifty cases. Dis Colon Rectum. 1975 Apr; 18 (3): $237-43$.

28. Halligan S, Bartram CI. Is barium trapping in rectoceles significant? Dis Colon Rectum. 1995 Jul; 38(7): 764-8.

29. Karlbom U, Graf W, Nilsson S, et al. Does surgical repair of a rectocele improve rectal emptying? Dis Colon Rectum. 1996 Nov; 39(11): 1296-302.

30. Heriot AG, Skull A, Kumar D. Functional and physiological outcome following transanal repair of rectocele. Br J Surg. 2004; 91 : 1340-4.

31. Roman H, Michot F. Long term outcomes of transanal rectocele repair. Dis Colon Rectum. 2005; 48: 510-7.

32. Meschia M, Buonaguidi A, Pifarotti P, et al. Prevalence of anal incontinence in women with symptoms of urinary incontinence and genital prolapse. Obstet Gynecol. 2002 Oct; 100(4): 719-23.

Journal of the Anus, Rectum and Colon is an Open Access journal distributed under the Creative Commons Attribution-NonCommercial-NoDerivatives 4.0 International License. To view the details of this license, please visit (https://creativ ecommons.org/licenses/by-nc-nd/4.0/). 